\title{
The concept of control of COPD in clinical practice
}

\author{
This article was published in the following Dove Press journal: \\ International Journal of COPD \\ 12 December 2014 \\ Number of times this article has been viewed
}

\author{
Juan José Soler-Cataluña ${ }^{1,2}$ \\ Bernardino Alcázar- \\ Navarrete ${ }^{3}$ \\ Marc Miravitlles 2,4 \\ 'Pneumology Department, Hospital \\ Arnau de Vilanova, Valencia, Spain; \\ ${ }^{2}$ CIBER de Enfermedades Respiratorias \\ (CIBERES), ${ }^{3}$ Respiratory Department, \\ Hospital de Alta Resolucion, Granada, \\ Spain; ${ }^{4}$ Pneumology Department, \\ Hospital Universitari Vall d'Hebron, \\ Barcelona, Spain
}

\begin{abstract}
Treatment of chronic obstructive pulmonary disease (COPD) requires a personalized approach according to the clinical characteristics of the patients, the level of severity, and the response to the different therapies. Furthermore, patients with the same level of severity measured by the degree of airflow obstruction or even with multidimensional indices may have very different symptoms and limitations for daily activities. The concept of control has been extensively developed in asthma but has not been defined in COPD. Here, we propose a definition of COPD control based on the concepts of impact and stability. Impact is a crosssectional concept that can be measured by questionnaires such as the COPD Assessment Test or the Clinical COPD Questionnaire. Alternatively, impact can be assessed by the degree of dyspnea, the use of rescue medication, the level of physical activity, and sputum color. Stability is a longitudinal concept that requires the absence of exacerbations and deterioration in the aforementioned variables or in the COPD Assessment Test or Clinical COPD Questionnaire scores. Control is defined by low impact (adjusted for severity) and stability. The concept of control in COPD can be useful in the decision making regarding an increase or decrease in medication in the stable state.
\end{abstract}

Keywords: COPD, control, CAT, CCQ, exacerbations, prognosis

\section{Introduction}

Chronic obstructive pulmonary disease (COPD) is very heterogeneous and thus, different authors have suggested the need for individualized treatment considering the different clinical characteristics and severity of each patient. ${ }^{1-3}$ To a certain extent, the Spanish Guidelines for COPD (GesEPOC) represent a model of transition toward personalized medicine. ${ }^{4}$ In these guidelines pharmacological treatment is established with a combination of two essential elements: a) the determination of the clinical phenotype, and b) evaluation of the level of severity with the use of a multidimensional index. Multiple therapeutic alternatives emerge from the interaction between these two axes (clinical phenotype and the level of severity), constituting the first step toward individualization of treatment, which has been followed by other national clinical guidelines. ${ }^{5}$

Evaluation of the clinical phenotype seeks the identification of groups of patients with similar characteristics presenting a similar response to different treatments and with similar clinical outcomes. ${ }^{6}$ Although multiple phenotypes may be considered with this definition, the four which may be deemed as clinically more relevant and which require differential treatment are: the non-exacerbator phenotype, mixed COPDasthma, exacerbator with emphysema, and exacerbator with chronic bronchitis. 
This approach groups patients with a similar therapeutic response to individualized treatment insofar as possible. ${ }^{2-4}$

With regard to severity, the second axis guiding pharmacological treatment, GesEPOC proposes five levels of severity according to a multidimensional classification essentially based on the BODE index (for Body mass index, Obstruction, Dyspnea and Exercise), ${ }^{7}$ and also, to a lesser extent, on the BODEx index (for Body mass index, Obstruction, Dyspnea and Exacerbations), ${ }^{8}$ a modification of the previous index in which the distance in the 6-minute walking test is replaced by the frequency of severe exacerbations. This classification essentially refers to prognostic severity which helps to identify the risk of patient death while also being useful for predicting the risk of exacerbations and hospitalizations. ${ }^{9}$ It is, therefore, a weighted scale of risk of the patient developing future complications.

However, this approach to the clinical situation of the patient does not allow the identification of changes in the day to day activity or symptoms of the patient which may require modifications in the treatment. Each clinical phenotype and each level of severity involves patients with a different expression of their disease with changes in their state and, thus, the concept of disease control may help to better assess the state of the patients and their response to treatment. This article includes a reflection on the need for this third axis (control of the disease) in therapeutic decision making and extends the initial proposal recently published. ${ }^{10}$

\section{What is control in COPD?}

The classification of phenotypes and levels of severity does not allow significant changes to be detected in the clinical status of the patients in response to modifications in treatment. For example, an exacerbator may increase the frequency of exacerbations without modifying the level of severity, or similarly, a non-exacerbator may increase the grade of dyspnea affecting the daily activities but without increasing the level of severity. There is no doubt that in both situations the physician interprets that the patient is not well controlled and requires some change in treatment. Thus, beyond the prognostic severity, many clinicians have suggested the need to include criteria which help to define the current clinical situation of the patient and, at the same time, provide knowledge of the temporal evolution of the disease with easy identification of possible changes. On one hand, the current clinical situation of the patient is a transversal and static assessment corresponding to a specific moment which will hereafter be referred to as "impact". However, the temporal evolution of this impact is a dynamic term which needs at least two observations over time and is framed within the concept of clinical stability. From the

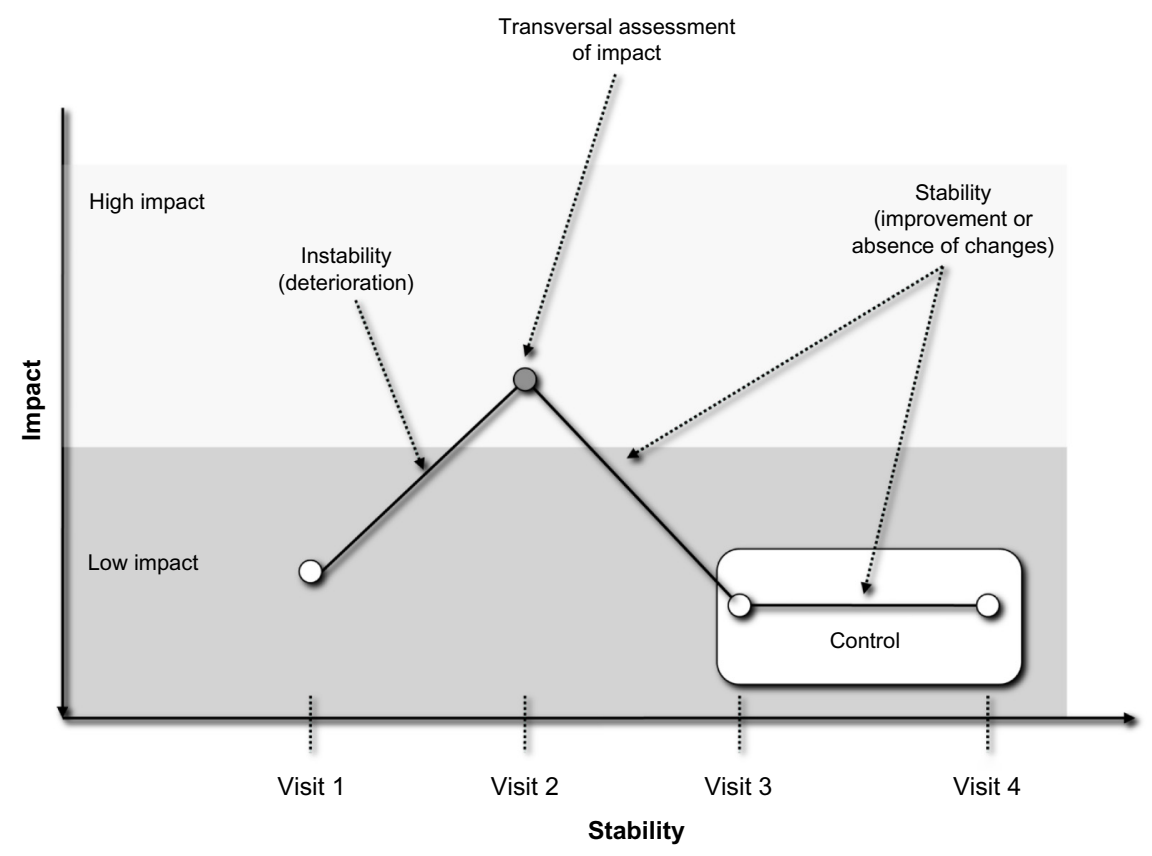

Figure I Representation of the concept of impact, stability, and control in COPD.

Notes: The circles represent the transversal measurement of the clinical situation at different times (impact); the lines show the analysis of the changes (degree of stability) and the gray area marks the concept of control understood as the desirable situation in which a condition of low impact is maintained over a long period of time according to the severity of the disease. Copyright (C) 2014 European Respiratory Society. Reproduced with permission of the European Respiratory Society. Eur Respir J erj00644-20 I4; published ahead of print July 25, 2014, doi:10.1183/09031936.00064414.10

Abbreviation: COPD, chronic obstructive pulmonary disease. 
interaction of these two concepts of impact and stability a new dimension is derived which we will denominate "control of COPD" (Figure 1).

In asthma the term "control" has been used for years and is defined by the absence of limitation in activities, absence of nocturnal symptoms, minimum or no diurnal symptoms, minimum or no need for rescue treatment, absence of exacerbations, and normal pulmonary function. ${ }^{11,12}$ Evaluation of the grade of control in asthma is transversal and static and does not consider its evolution over time. In most patients with asthma included in clinical trials, control of the disease may be achieved and maintained, although this control is often not achieved in the patients observed in studies of usual clinical practice. ${ }^{13-15}$ In the case of COPD a similar concept of disease control would be very difficult to achieve, among other reasons because normalization of pulmonary function is not possible (by definition) and many patients remain symptomatic or with limitations in their activities and even present exacerbations despite treatment. However, a favorable or optimal clinical situation may often be achieved in relation to the basal severity of the disease and may also remain stable over time, thereby making it possible to define a concept of control in COPD while recognizing differential aspects in comparison with asthma.

The therapeutic scheme of COPD recommends an increase in the intensity of the treatment according to an increase in the level of severity. ${ }^{16}$ However, the step from one level of severity to another requires a considerable change in the conditions of the disease and, thus, therapeutic decisions in daily practice are more often based on the perception, sometimes subjective, made by the physician regarding alterations in the evolution of the disease. These alterations may not imply changes in the level of severity, but should be reflected in the concept of control. The evaluation of the grade of control would be much more dynamic and would allow objective assessment of the changes in the clinical status of the patient which may be susceptible to changes in the treatment within the same level of severity.

\section{Evaluation of control in a population of patients with COPD}

A cohort of patients not previously published was recruited including 59 patients with mild to moderate COPD according to the GesEPOC classification (BODE or BODEx $\leq 4$ points) with a mean age of 71 (standard deviation $[\mathrm{SD}]=9$ ) years and a post-bronchodilator forced expiratory volume in 1 second $\left(\mathrm{FEV}_{1}\right)(\%)$ of $55 \%(\mathrm{SD}=17 \%)$. In the first visit the clinical phenotype, the level of severity, and the COPD Assessment Test (CAT) score, as measure of impact, were determined. In a follow-up visit 3 months later the CAT score was repeated assessing both the impact as well as the changes observed during this time period (stability) with the aim of identifying the degree of control of COPD.

Fifty-five percent of the patients presented a nonexacerbator phenotype, $18 \%$ were labeled as a mixed phenotype; another 14\% were exacerbators with emphysema, and $13 \%$ were classified as exacerbators with chronic bronchitis. The level of severity using the BODE index was mild (I) in $62 \%$ of the patients and moderate (II) in $38 \%$. A low impact was present in $61 \%$ of the patients and $71 \%$ were classified as

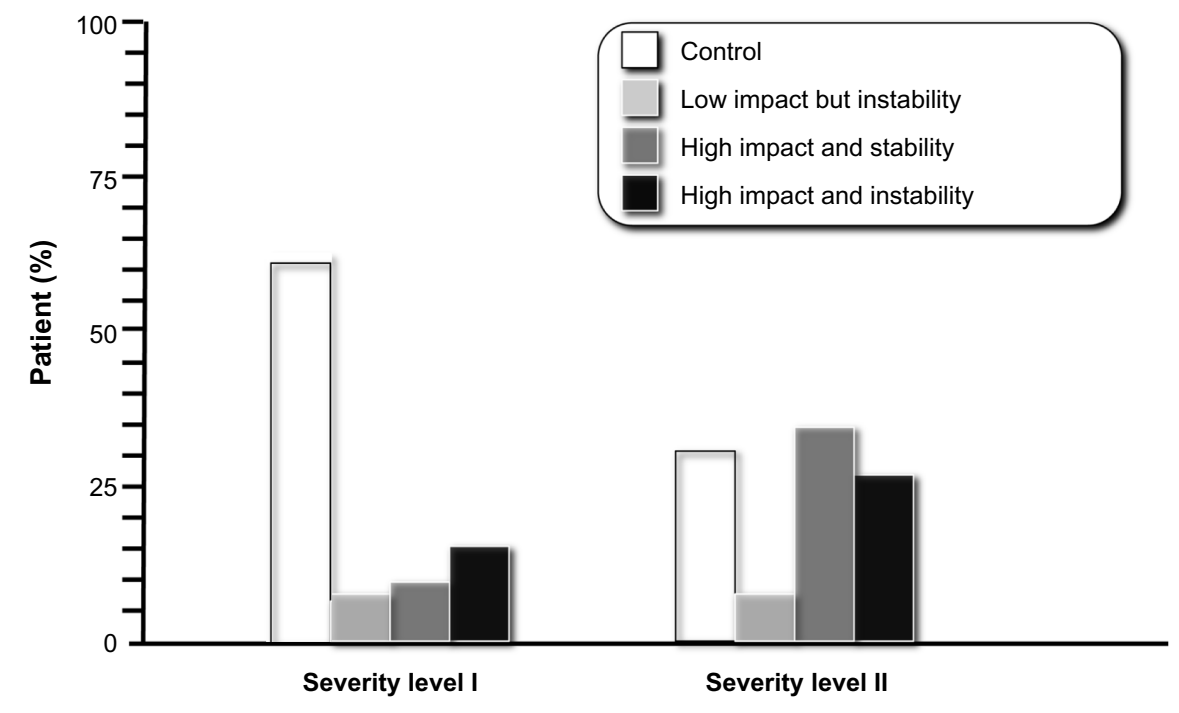

Figure 2 Distribution of the degree of control for levels I and II of severity, using the COPD Assessment Test scores. Abbreviation: COPD, chronic obstructive pulmonary disease. 
stable. Finally, $51 \%$ of the cases fulfilled criteria of control. Figure 2 shows the distribution of the degree of control among the patients in the cohort.

As the severity of the disease increases, the proportion of patients achieving control diminishes. However, among mild patients, up to $12.5 \%$ were not controlled due to both high impact and instability, with this value surpassing $25 \%$ in the moderate cases.

\section{Concept of control}

Impact: prognostic severity and impact are static concepts which are somewhat related but are not necessarily the same. While severity assesses the future risk of death and other complications, ${ }^{7-9}$ clinical impact refers to the current repercussion the disease has on the patient. According to the ECLIPSE (Evaluation of COPD Longitudinally to Identify Predictive Surrogate Endpoints) ${ }^{17}$ study, we may have patients with a different degree of dyspnea for the same level of prognostic severity defined by both $\mathrm{FEV}_{1}$ and even by the BODE index. Dyspnea is seldom referred by patients in Global Initiative on Obstructive Lung Disease (GOLD) stage IV, while others in GOLD stage I may present with degree 3 or 4 dyspnea in the modified scale of the Medical Research Council. This same distribution is also observed for other variables of interest such as the health-related quality of life (HRQoL) or the distance covered in the 6-minute walking test. ${ }^{17}$ These observations suggest that the clinical impact may be different for the same level of prognostic severity, thereby indicating that other factors not identified may contribute to the current clinical situation of the patient.

The impact of any disease depends on how the patients perceive the disease and modify their daily life. ${ }^{1}$ This perception varies greatly among individuals with COPD similarly to what occurs with asthma. ${ }^{18}$ At present there is growing interest in knowing the opinion of the patients, their worries, and preferences. On many occasions this perception is not reflected in the functional or biological markers used to monitor the disease and may not even be fully perceived by the physicians. ${ }^{19}$ It is therefore necessary to develop tools able to collect this type of information with the so-called "patient-reported outcomes" (PROs). A PRO is defined as a dimension of the disease which is obtained directly from the patient without the need for performing biological or functional tests. The scales of dyspnea, physical activity or HRQoL questionnaires are some of the best known examples of PROs which help to evaluate clinical impact. ${ }^{20}$

Impact may be classified as low or high and should always be adjusted for the level of disease severity since, for example, a patient with very severe COPD would very unlikely have an excellent health status. We propose that the determination of clinical impact must include assessment of the degree of dyspnea, the use of rescue medication, the limitations in daily physical activity, and the usual sputum color. As an alternative, questionnaires such as the $\mathrm{CAT}^{21}$ or the Clinical COPD Questionnaire (CCQ) may be used. ${ }^{22}$

The CAT or the CCQ are simple, specific, brief questionnaires which are easy to apply in clinical practice and aim to quantify the impact of the disease. They are complementary measures to clinical assessment and present an excellent correlation with tools measuring the HRQoL such as the St George's Respiratory Questionnaire. Significant variations have been described in the CCQ or the CAT scores within the same level of COPD severity, thereby suggesting their complementary utility. In addition, the sensitivity to change after an exacerbation has been validated. ${ }^{23,24}$ In our opinion, the simplicity and ease of use of these questionnaires make them ideal tools to assess clinical impact.

Stability: stable condition is defined as not easily moved, upset, or changed; firm; steady. ${ }^{25}$ By translating this definition to COPD, we can understand that stability is a clinical situation which remains without significant changes over a period of time or which returns to the previous state after an alteration (exacerbation).

According to this definition and to adequately establish the stability of a patient with COPD the following two criteria must be fulfilled:

a. absence of exacerbation, including the inherent phase of recovery from the exacerbation;

b. absence of significant clinical worsening during a period of time, that is, that stability includes the absence of significant clinical changes and/or the presence of improvement (positive changes).

The questionnaires of clinical control such as CAT or CCQ may also be potentially useful to evaluate clinical changes over time. ${ }^{23,24}$ In the case of the CAT it has been described that a change of $>2$ points may indicate clinically significant deterioration, ${ }^{26}$ with the same occurring with a change $>0.4$ points for the CCQ. ${ }^{27}$

\section{Absence of exacerbation}

Exacerbation in COPD is defined as an acute episode of increase in the respiratory symptoms beyond the daily variations. ${ }^{4}$ Therefore, stability implies that the patient is not in a period of exacerbation. This aspect may be difficult to determine; with the use of symptom diaries it has been established that up to $23 \%$ of patients may remain symptomatic up to 30 days after 
the onset of an exacerbation. ${ }^{28}$ Accordingly, an exacerbation may be considered resolved $\sim 4$ weeks after having finished the treatment or at 6 weeks after the onset, independently of the treatment administered. ${ }^{29-31}$ If symptoms reappear during this period of time the patient is considered to have had a recurrence of the exacerbation. Thus, the first criterion necessary to define stability is to ensure that the patient is not in a period of exacerbation (Figure 3). However, not all patients who are no longer in a period of exacerbation can be considered stable. Indeed, some patients may be unstable even without an exacerbation. This last state may possibly be the consequence of a recent exacerbation or a warning of imminent risk of a new exacerbation, thereby representing a situation of fragility which should rapidly be corrected to minimize the consequences. With the use of symptom diaries, Aaron et $\mathrm{al}^{32}$ observed that nearly $50 \%$ of exacerbations were preceded by several days of instability in which the scores of the EXAcerbations of Chronic pulmonary disease Tool (EXACT) questionnaire showed significant changes compared to the baseline situation. Identification of these periods of instability could, perhaps, allow early therapeutic intervention to prevent the exacerbations and therewith provide greater utility to the concept of clinical stability.

\section{Absence of clinical changes over time}

The concept of stability implies an absence of significant changes over time or an improvement. The length of time necessary to evaluate this absence of worsening remains to be established. Following the parallelism with asthma and the concept of control, most guidelines of clinical practice recommend assessment of the state of control every 3 months. ${ }^{9-11}$ Our proposal is that a period of at least 3 months without clinically significant changes may be a reasonable length of time to establish the definition of stability or "short-term" stability; when stability is prolonged beyond 6 months it can be defined as "sustained" stability. The appearance of exacerbations during the observation period is a clear example of clinical instability, as is clinical worsening measured with the CAT or the CCQ. ${ }^{22-24}$

\section{Definition of control in COPD}

In contrast with what occurs in asthma in which disease control is a cross-sectional, static measurement which does not consider the previous severity of the patient, the control of COPD is a dynamic concept requiring evaluation of the current impact (transversal assessment) and analysis of the possible changes over time or stability (longitudinal assessment). In addition, evaluation of impact should be adjusted to the prognostic severity of the patient, since increases in severity make it more difficult to achieve health states with scarce clinical repercussion (low impact).

We will therefore define control of COPD as maintenance of a situation of low impact over time adapted to the severity of the disease itself. Therefore, in order to establish a situation of optimal control of COPD the following criteria should be fulfilled:

1. low impact according to the baseline severity of the disease;

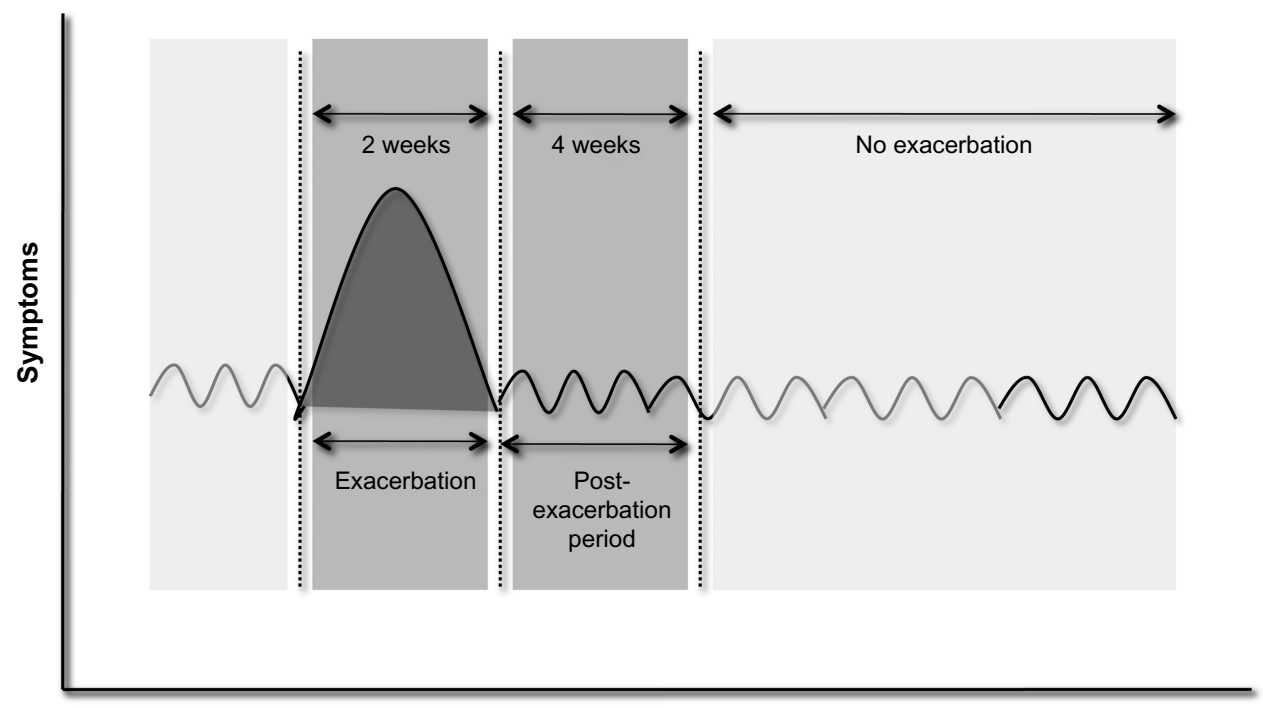

Time

Figure 3 Absence of exacerbation.

Notes: A patient is considered to enter a period free of exacerbation when at least 4 weeks have passed since the treatment for the previous exacerbation has been completed (or 6 weeks since the initiation of the same). 
2. stability defined by the absence of significant clinical worsening and by the absence of exacerbations in the last 3 months.

Patients fulfilling these criteria may be classified as controlled and the term "not controlled" should be reserved for the remaining cases. Ideally, the degree of control should: a) be related to the underlying biological activity of the disease (controlled patients should have less biological activity); b) be associated with different clinically relevant outcomes (greater control, better outcomes); and c) be able to be modified by the treatment in that the therapeutic objective involves seeking control for each level of basal severity. Thus, this new dimension should help health care professionals to make therapeutic decisions (increase or decrease intensity of treatment) so that the phenotypic and severity classification allows the classification of the patient and orientation of treatment on the initial visit and helps in determining the starting point. Afterward, the treatment should be modified according to the degree of control of the disease. Likewise, this new concept may also help to consider new diagnostic tests in search of destabilizing factors and/or more adequately plan the clinical follow-up of the patient.

\section{Possible implications of the degree of control in COPD \\ Control and biological activity}

Similar to what occurs in asthma, in which non-controlled patients present greater levels of inflammation, ${ }^{13}$ the degree of control in COPD is very likely related to the underlying biological activity. The activity of a disease reflects the intensity of the biological mechanisms causing it. ${ }^{1,33}$ This concept has been scarcely studied in COPD, but it has to be differentiated from the concepts of severity and impact. ${ }^{34}$ While change in markers of disease severity may be considered markers of disease activity, these quantify a single aspect of the disease activity in COPD rather than measuring the overall disease process; therefore, there is a need for new biomarkers of disease activity. ${ }^{34}$ The most appropriate marker of activity in COPD remains unknown; however, different mediators of inflammation and/or oxidative stress have been associated with the presence of frequent exacerbations. ${ }^{35-37}$ It has recently been demonstrated that the presence of increased circulating leukocytes, C-reactive protein and/or fibrinogen in plasma is related to the risk of developing new exacerbations. ${ }^{36}$ Repeated determinations of plasma biomarkers of inflammation in COPD have also allowed the identification of "persistently inflamed" patients presenting a greater frequency of exacerbations, ${ }^{38}$ and elevated plasma concentrations of fibrinogen have been associated with patients with an elevated consumption of health care resources. ${ }^{39}$ These studies suggest that the lack of control in COPD may be associated with greater inflammatory activity, although the most adequate markers remain to be defined.

\section{Control and future risk of clinical outcomes}

Although the level of disease severity helps to identify the risk of death and complications, the degree of control may also be related to clinical outcomes so that the worse the control within the same level of severity, the worse the consequences. The level of physical activity is an independent prognostic factor of the severity of the disease, ${ }^{40,41}$ and the same is true regarding the impairment of HRQoL. ${ }^{42} \mathrm{~A}$ history of frequent exacerbations is also associated with a greater risk of new exacerbations. ${ }^{43}$ As mentioned before, approximately half of the exacerbations of COPD are preceded by a prodromic period of an increase in symptoms of several days. The detection of these days of bad disease control could help to adopt measures aimed at preventing the exacerbations and may be implemented in self-management programs. $^{32}$

\section{Degree of control and adjustment of treatment}

Control in COPD should be an achievable objective for all patients independently of the level of disease severity. To do this it may sometimes be necessary to increase the medication while in other cases the treatment schedule may be maintained or even reduced in patients who remain controlled over time, with the objective of identifying the minimum effective medication. This approach could help to adjust treatment in each patient thereby avoiding both the under- and over-use of drugs and achieve a better disease evolution with minimum medication necessary. Recent studies have shown that, in general, moderate patients are over-treated and some severe patients are under-treated. ${ }^{44,45}$ In this sense, an increasing number of studies have been performed to analyze the possible reduction or suppression of drugs such as inhaled corticosteroids in some patients with COPD. ${ }^{46,47}$

\section{The proposal: control in COPD Identification of the degree of control}

We propose to determine the degree of control of the patient as a complementary measure to the evaluation of the clinical phenotype and the level of prognostic severity of the disease (Figure 4). This evaluation will be performed every time the patients visit their physician outside the periods of exacerbation and will obligatorily include assessment of impact (Tables 1 and 2) and stability (Table 3). 


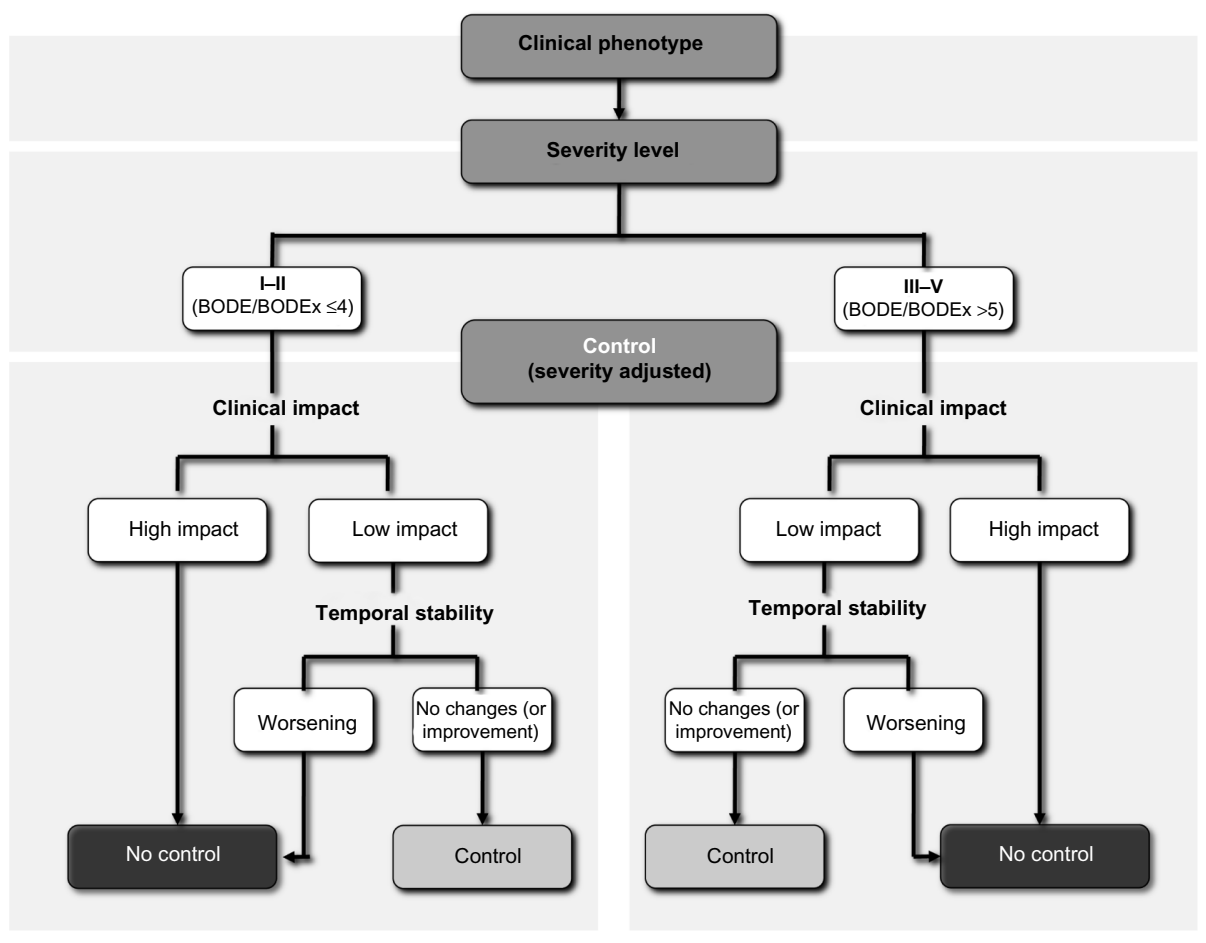

Figure 4 Evaluable dimensions of chronic obstructive pulmonary disease (COPD).

Notes: Evaluation of a patient with COPD should include the determination of: a) the clinical phenotype; b) the level of prognostic severity; and c) the degree of control. Control is achieved in COPD when the impact is low (adjusted to the corresponding level of severity) with scarce clinical changes or improvement or changes in the last 3 months. No control is observed when the patient presents significant worsening (instability) or has a moderate or high clinical impact. BODE index: for Body mass index, Obstruction, Dyspnea and Exercise. BODEx index: for Body mass index, Obstruction, Dyspnea and Exacerbations.

Control will be achieved when the patient is in a situation of low impact adjusted to the prognostic severity and stability with no detection of significant clinical worsening or exacerbations within the previous 3 months or even with an improvement observed in the symptoms or in the clinical questionnaires such as the CAT or the CCQ (Table 3).

Table I Criteria necessary to establish the impact of patients with mild to moderate severity (BODE/Ex $\leq 4$ points)

\begin{tabular}{lll}
\hline & \multicolumn{2}{l}{$\begin{array}{l}\text { Mild to moderate severity } \\
\text { (BODE/BODEx } \leq 4 \text { points) }\end{array}$} \\
\cline { 2 - 3 } & Low impact & High impact \\
\hline $\begin{array}{l}\text { Clinical evaluation } \\
\text { Dyspnea (mMRC) }\end{array}$ & $0-1$ & $\geq 2$ \\
Rescue medication & $\leq 3$ times in the & $>3$ times in \\
& last week & the last week \\
Daily physical activity* & $\geq 60$ minutes & $<60$ minutes \\
(time walked per day) & & \\
Sputum color & Absent or white & Dark \\
CAT & $\leq 10$ & $>10$ \\
CCQ & $\leq 1$ & $>1$
\end{tabular}

Notes: High impact was considered when fulfilling one or more of the criteria established. *Time walked per day: includes the total time the patient has walked whether at home or outside. BODE index: for Body mass index, Obstruction, Dyspnea and Exercise. BODEx index: for Body mass index, Obstruction, Dyspnea and Exacerbations. Abbreviations: CAT, COPD Assessment Test; CCQ, Clinical COPD Questionnaire; COPD, chronic obstructive pulmonary disease; mMRC, modified scale of the Medical Research Council.

\section{Adjustment of the treatment according to the degree of control}

Patients classified as non-controlled should be evaluated more in-depth in search of the possible causes (persistence in smoking habits, bad inhalatory technique, poor treatment compliance, comorbidities, chronic bronchial infection,

Table 2 Criteria necessary to establish the impact of patients with severe and very severe COPD (BODE/Ex $>5$ points)

\section{Severe/very severe COPD} (BODE/BODEx $>5$ points)

\begin{tabular}{lll} 
& Low impact & High impact \\
\hline Clinical evaluation & & \\
Dyspnea (mMRC) & $0-2$ & $\geq 3$ \\
Rescue medication & $\leq 2$ times a day & $>2$ times a day \\
$\begin{array}{l}\text { Daily physical activity* } \\
\text { (time walking per day) }\end{array}$ & $\geq 30$ minutes & $<30$ minutes \\
$\begin{array}{l}\text { Sputum color } \\
\text { Questionnaires of clinical control }\end{array}$ & Absent or white & Dark \\
CAT & $\leq 20$ & $>20$ \\
CCQ & $\leq 2$ & $>2$ \\
\hline
\end{tabular}

Notes: High impact was considered when fulfilling one or more of the criteria established. *Time walked per day: includes the total time the patient has walked whether at home or outside. BODE index: for Body mass index, Obstruction, Dyspnea and Exercise. BODEx index: for Body mass index, Obstruction, Dyspnea and Exacerbations.

Abbreviations: CAT, COPD Assessment Test; CCQ, Clinical COPD Questionnaire; COPD, chronic obstructive pulmonary disease; mMRC, modified scale of the Medical Research Council. 
Table 3 Criteria necessary to establish the degree of control

\begin{tabular}{|c|c|c|}
\hline & Control & No control \\
\hline \multicolumn{3}{|l|}{ Current clinical situation } \\
\hline \multirow[t]{2}{*}{ Impact (adjusted according to severity) } & Low & High \\
\hline & $\begin{array}{l}\text { and all of } \\
\text { the following }\end{array}$ & $\begin{array}{l}\text { or any of } \\
\text { the following }\end{array}$ \\
\hline \multicolumn{3}{|l|}{ Clinical changes in the last 3 months } \\
\hline Changes in the CAT & $<2$ & $\geq 2$ \\
\hline Changes in the $\mathrm{CCQ}$ & $<0.4$ & $\geq 0.4$ \\
\hline Exacerbations in the last 3 months & No & Yes \\
\hline
\end{tabular}

Notes: Control: requires low impact and also scarce clinical changes. The patient is considered not controlled whenever there is a high impact or when there is a significant worsening.

Abbreviations: CAT, COPD Assessment Test; CCQ, Clinical COPD Questionnaire; COPD, chronic obstructive pulmonary disease.

exacerbations, etc). On other occasions, in which the cause is not identified or the correction of the cause is not sufficient, the best option will be to add/increase the maintenance medication and/or consider other non-pharmacological options such as respiratory rehabilitation or oxygen therapy. If the patient is classified as controlled the initial recommendation is to maintain the treatment schedule and in cases in which this situation persists for more than 6 months (sustained control), evaluate a possible reduction in the usual treatment.

In conclusion, we believe that on the path initiated toward personalization of treatment in COPD not only is the clinical phenotype of the patient identified and the level of prognostic severity (level of risk) established, but it is also necessary to have a tool to evaluate the clinical situation of the patient and the recent evolution at every medical visit. ${ }^{48}$ This proposal introduces the possibility of down- or up-scaling the previous therapeutic regime. The aim of this article was to introduce the concept of control in COPD and stimulate the debate. All the suppositions made here should be reviewed and evaluated with studies designed to this end before translation to clinical practice.

\section{Disclosure}

Juan José Soler-Cataluña has received speaker fees and/ or consulting fees from Boehringer Ingelheim, Pfizer, AstraZeneca, Bayer Schering, Novartis, Takeda-Nycomed, Merck, Sharp and Dohme, Almirall, Grupo Ferrer, GlaxoSmithKline, and Vifor Pharma.

Bernardino Alcázar-Navarrete has received speaker fees and/or consulting fees from Almirall, AstraZeneca, Boehringer Ingelheim, Chiesi, Grupo Ferrer, GSK, Laboratorios Menarini, Novartis, Pfizer, and Takeda.

Marc Miravitlles has received speaker fees from Almirall, Boehringer Ingelheim, Pfizer, AstraZeneca, Chiesi, Esteve, GlaxoSmithKline, Menarini, Grifols, Nycomed, and
Novartis, and consulting fees from Almirall, Boehringer Ingelheim, Pfizer, GlaxoSmithKline, Gebro Pharma, CLS Behring, Grupo Ferrer, MediImmune, Novartis, Grifols, and Nycomed.

\section{References}

1. Agusti A, MacNee W. The COPD control panel: towards personalised medicine in COPD. Thorax. 2013;68(7):687-690.

2. Miravitlles M, Soler-Cataluña JJ, Calle M, Soriano JB. Treatment of COPD by clinical phenotypes: putting old evidence into clinical practice. Eur Respir J. 2013;41(6):1252-1256.

3. McDonald V, Higgins I, Wood LG, Gibson PG. Multidimensional assessment and tailored interventions for COPD: respiratory utopia or common sense? Thorax. 2013;68(7):691-694.

4. Miravitlles M, Soler-Cataluña JJ, Calle M, et al. Spanish Guideline for COPD (GesEPOC). Update 2014. Arch Bronconeumol. 2014;50 Suppl 1: $1-16$.

5. Koblizek V, Chlumsky J, Zindr V, et al. Chronic Obstructive Pulmonary Disease: Official diagnosis and treatment guidelines of the Czech Pneumological and Phthisiological Society; a novel phenotypic approach to COPD with patient-oriented care. Biomed Pap Med Fac Univ Palacky Olomouc Czech Repub. 2013;157(2):189-201.

6. Han MK, Agusti A, Calverley PM, et al. Chronic obstructive pulmonary disease phenotypes: the future of COPD. Am J Respir Crit Care Med. 2010;182(5):598-604.

7. Celli BR, Cote CG, Marín JM, et al. The body-mass index, airflow obstruction, dyspnea, and exercise capacity index in chronic obstructive pulmonary disease. $N$ Engl J Med. 2004;350(10):1005-1012.

8. Soler-Cataluña JJ, Martínez-García MA, Sánchez LS, Tordera MP, Sánchez PR. Severe exacerbations and BODE index: two independent risk factors for death in male COPD patients. Respir Med. 2009;103(5): 692-699.

9. Marín JM, Carrizo SJ, Casanova C, et al. Prediction of risk of COPD exacerbations by the BODE index. Respir Med. 2009;103(3): 373-378.

10. Soler-Cataluña JJ, Alcazar-Navarrete B, Miravitlles M. The concept of control in COPD: a new proposal for optimising therapy. Eur Respir J. 2014;44(4):1072-1075.

11. Global Initiative for Asthma. Global Strategy for Asthma Management and Prevention 2014. Available from: http://www.ginasthma.org/local/uploads/ files/GINA_Report_2014_Aug12.pdf. Accessed November 13, 2014.

12. Guía española para el manejo del asma (GEMA 2009) [Spanish Guideline on the Management of Asthma]. Arch Bronconeumol. 2009; 45(Suppl 7):2-35. Spanish.

13. Bateman ED, Boushey HA, Bousquet J, et al. Can guideline-defined asthma control be achieved? The Gaining Optimal Asthma ControL study. Am J Respir Crit Care Med. 2004;170(8):836-844.

14. Cazzoletti L, Marcon A, Janson C, et al. Asthma control in Europe: a real-world evaluation based on an international population-based study. J Allergy Clin Immunol. 2007;120(6):1360-1367.

15. Chapman KR, Boulet LP, Rea RM, Franssen E. Suboptimal asthma control: prevalence, detection and consequences in general practice. Eur Respir J. 2008;31(2):320-325.

16. Rabe KF, Hurd S, Anzueto A, et al. Global strategy for the diagnosis, management, and prevention of chronic obstructive pulmonary disease. GOLD executive summary. Am J Respir Crit Care Med. 2007;176(6): 532-555.

17. Agustí A, Calverley PMA, Celli B, et al. Characterisation of COPD heterogeneity in the ECLIPSE cohort. Respir Res. 2010;11:122.

18. Davis SQ, Permutt Z, Permutt S, et al. Perception of airflow obstruction in patients hospitalized for acute asthma. Ann Allergy Asthma Immunol. 2009;102(6):455-461.

19. Miravitlles M, Ferrer J, Baró E, Lleonart M, Galera J. Differences between physician and patient in the perception of symptoms and severity in COPD. Respir Med. 2013;107(12):1977-1985. 
20. Jones P, Miravitlles M, van der Molen T, Kulich K. Beyond FEV1 in COPD: a review of patient-reported outcomes and their measurement using a new generation of instruments. Int J Chron Obst Pulm Dis. 2012;7:697-709.

21. Jones PW, Harding G, Berry P, Wiklund I, Chen WH, Kline Leidy N. Development and first validation of the COPD Assessment Test. Wur Respir J. 2009;34(3):648-654.

22. Van der Molen T, Willemse BWM, Schokker S, ten Hacken NHT, Postma DJ, Juniper EF. Development, validity and responsiveness of the clinical COPD questionnaire. Health Qual Life Outcomes. 2003;1:13.

23. Agustí A, Soler JJ, Molina J, et al. Is the CAT questionnaire sensitive to changes in health status in patients with severe COPD exacerbations? COPD. 2012;9(5):492-498.

24. Miravitlles M. García-Sidro P, Fernández-Nistal A, Buendía MJ, Espinosa de los Monteros MJ, Molina J. Course of COPD assessment test (CAT) and clinical COPD questionnaire (CCQ) scores during recovery from exacerbations of chronic obstructive pulmonary disease. Health Qual Life Outcomes. 2013;11:147.

25. Oxford Dictionaries. Available from: http://www.oxforddictionaries. com/. Accessed October 16, 2014.

26. Kon SS, Canavan JL, Jones SE, et al. Minimum clinically important difference for the COPD Assessment Test: a prospective analysis. Lancet Respir Med. 2014;2(3):195-203.

27. Kocks JW, Tuinenga MG, Uil SM, van den Berg JW, Stahl E, van der Molen T. Health status measurement in COPD: the minimal clinically important difference of the clinical COPD questionnaire. Respir Res. 2006;7:62.

28. Perera WR, Hurst JR, Wilkinson TM, et al. Inflammatory changes, recovery and recurrence at COPD exacerbation. Eur Respir J. 2007;29(3):527-534

29. Soler-Cataluña JJ, Rodriguez-Roisin R. Frequent chronic obstructive p8lmonary disease exacerbators: how much real, how much fictitious? COPD. 2010;7(4):276-284.

30. Seemungal TA, Donaldson GC, Bhowmik A, Jeffries DJ, Wedzicha JA Time course and recovery of exacerbations in patient with chronic obstructive pulmonary disease. Am J Respir Crit Care Med. 2000; 161(5):1608-1613.

31. Spencer S, Jones PW; GLOBE study group. Time course of recovery of health status following an infective exacerbation of chronic bronchitis. Thorax. 2003;58(7):589-593.

32. Aaron SD, Donaldson GC, Whitmore GA, Hurst JR, Ramsay T, Wedzicha JA. Time course and pattern of COPD exacerbation onset. Thorax. 2012;67(3):238-243.

33. Vestbo J, Rennard S. Chronic obstructive pulmonary disease biomarkers(s) for disease activity needed-urgently. Am J Respir Crit Care Med. 2010;182(7):863-864.

34. Carter RI, Stockley RA. Disease "activity", "severity" and "impact": interrelationships in COPD; is a measure of disease "activity" the Holy Grail for COPD, or a variable impossible to quantify? COPD. 2014;11(4):363-367.
35. Tumkaya M, Atis S, Ozge C, Delialioglu N, Polat G, Kanik A Relationship between airway colonization, inflammation and exacerbation frequency in COPD. Respir Med. 2007;101(4):729-737.

36. Patel IS, Seemungal TA, Wilks M, Lloyd-Owen SJ, Donaldson GC, Wedzicha JA. Relationship between bacterial colonisation and the frequency, character, and severity of COPD exacerbations. Thorax. 2002;57(9):759-764.

37. Thomsen M, Ingebrigtsen TS, Marrott JL, et al. Inflammatory biomarkers and exacerbations in chronic obstructive pulmonary disease. JAMA. 2013;309(22):2353-2361.

38. Agustí A, Edwards LD, Rennard SI, et al. Persistent systemic inflammation is associated with poor clinical outcomes in COPD: A novel phenotype. Plos One. 2012;7(5):e37483.

39. García-Polo C, Alcázar-Navarrete B, Ruiz-Iturriaga LA, et al. Factors associated with high resource utilisation among COPD patients. Respir Med. 2012;106(12):1734-1742.

40. García-Aymerich J, Lange P, Benet M, Schnohr P, Antó JM. Regular physical activity reduces hospital admission and mortality in chronic obstructive pulmonary disease: a population based cohort study. Thorax. 2006;61(9):772-778.

41. Miravitlles M, Cantoni J, Naberan K. Factors associated with low level of physical activity in patients with chronic obstructive pulmonary disease. Lung. 2014;192(2);259-265.

42. Sundh J, Janson C, Lisspers K, Montgomery S, Ställberg B. Clinical COPD Questionnaire score (CCQ) and mortality. Int J Chron Obstruct Pulmon Dis. 2012;7:833-842.

43. Hurst JR, Vestbo J, Anzueto A, et al. Susceptibility to exacerbation in chronic obstructive pulmonary disease. N Engl J Med. 2010;363(12): 1128-1138.

44. Miravitlles M, Sicras A, Crespo C, et al. Costs of COPD in relation to compliance with guidelines. A study in the Primary Care setting. Ther Adv Respir Dis. 2013;7(3):139-150.

45. Ghattas C, Dai A, Gemmel DJ, Award MH. Over diagnosis of chronic obstructive pulmonary disease in an underserved patient population. Int J Chron Obst Pulm Dis. 2013;8:545-549.

46. Al-Kassimi FA, Alhamad EH, Al-Hajjaj MS, Abba AA, Raddaoui E, Shaikh SA. Abrupt withdrawal of inhaled corticosteroids does not result in spirometric deterioration in chronic obstructive pulmonary disease: effect of phenotyping? Ann Thorac Med. 2012;7(4) 240-242.

47. Nadeem NJ, Taylor SJ, Eldridge SM. Withdrawal of inhaled corticosteroids in individuals with COPS - a systematic review and comment of trial methodology. Respir Res. 2011;12:107.

48. Lopez-Campos JL, Bustamante V, Muñoz X, Barreiro E. Moving towards patient-centered medicine for COPD management: multidimensional approaches versus phenotype-based medicine A critical view. COPD. 2014;11(5):591-602.
International Journal of COPD

\section{Publish your work in this journal}

The International Journal of COPD is an international, peer-reviewed journal of therapeutics and pharmacology focusing on concise rapid reporting of clinical studies and reviews in COPD. Special focus is given to the pathophysiological processes underlying the disease, intervention programs, patient focused education, and self management protocols.

\section{Dovepress}

This journal is indexed on PubMed Central, MedLine and CAS. The manuscript management system is completely online and includes a very quick and fair peer-review system, which is all easy to use. Visit http://www.dovepress.com/testimonials.php to read real quotes from published authors. 